\title{
Principais variações, desvios, parafilias e perversões
}

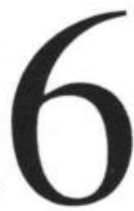

Nelson Vitiello*

Conceituam-se como desvios sexuais situações em que as manifestações de um ou de vários dos aspectos sociais do exercício da sexualidade não acompanha as da maioria das pessoas. Em outras palavras, seriam desvios as manifestações incomuns ou anormais, sendo aqui este último termo compreendido em seu sentido estatístico.

$\mathrm{Na}$ realidade, aqui como em qualquer outro aspecto, as manifestações assumem um caráter absolutamente personificado, não sendo possível encontrar 2 seres humanos com gostos e manifestações absolutamente iguais. Isso equivale a dizer que, de uma maneira ou de outra, todos nós somos portadores de desvios, em grau maior ou menor. São nesse sentido desvios a atração sexual que alguns homens às vezes relatam sentir por mulheres com leve grau de estrabismo, em fases iniciais da gestação, ou com determinadas características físicas. Seriam também desvios, nesse sentido, a atração que algumas mulheres sentem por homens de um certo grupamento racial, com pêlos nas costas, muito mais velhos, ou que fumem cachimbos, por exemplo. Como pode se ver, as preferências pessoais, desde que incomuns, podem ser encaradas como desvios.

* Doutor em Medicina. Terapeuta Sexual. Presidente da SBRASH. 
Reserva-se a denominação de desvio, entretanto, para aquelas situações em que o objeto de desejo, ou o alvo de excitabilidade, fogem bastante ao comum. É assim visto como um desvio, a atração sexual por pessoas do mesmo sexo (homossexualismo), ou o despertar de sensações eróticas ao se usar vestes típicas do sexo oposto (travestismo).

A maioria dos autores não faz uma distinção nítida entre variações, desvios, parafilias e perversões, não havendo uniformidade de conceituação nem de nomenclatura. O Conselho Científico da Sociedade Brasileira de Estudos em Sexualidade Humana (SBRASH) está formulando uma proposta para conceituar tais termos, que em breve será apresentada para discussão pelos profissionais interessados.

Independentemente do conceito que cada uma dessas palavras possa ter, apresentamos a seguir uma listagem atualizada dessas práticas. Obviamente, sendo o comportamento humano tão variado quanto é, fica muito difícil ter-se permanentemente uma listagem completa e atualizada, pois praticamente a cada dia são descritas novas práticas. Por isso, a listagem agora apresentada deve ser vista como uma atualização, e não como algo de definitivo.

Acrotomofilia - excitação com portadores de amputações. O desvio complementar é a apotemnofilia (ver esse termo).

Agonofilia - excitação com simulações de estrangulamento.

Agorafilia - excitação sexual em fazer sexo em lugares abertos ou em público.

Agrexofilia - excitação ao fazer sexo, sabendo que outras pessoas estão sabendo que, naquele momento, o portador está fazendo sexo. Alargamento genital - ver Stretching.

Algutofilia - excitação obtida através da água.

Aloerastia - o uso da nudez de uma terceira pessoa para excitar a parceria sexual.

Alopelia - caso particular de voyeurismo, é a excitação até o orgasmo pela visualização de outras pessoas fazendo sexo.

Alorgasmia - excitação obtida através da formulação de fantasias sexuais com outras pessoas que não a parceria.

Alotriorastia - excitação com pessoas de outras etnias.

Alfamegamia - excitação com parceiros de faixas etárias diferentes da do portador.

Amaurofilia - excitação por parceiros usando máscaras.

Anaclitismo - é o adulto que se erotiza com práticas peculiares da infância, tais como "mamar", ser banhado, usar fraldas etc. Sinônimo de infantilismo.

Analismo - ver Proctofilia.

Anastemafilia - atração sexual por parceria muito alta ou muito baixa. 
Anililagnia - desejo por mulheres idosas. É uma variante de gerontofilia.

Anisonogamistia - atração sexual por pessoas com grandes diferenças de idade, muito mais velhas (gerontofilia) ou muito mais novas.

Anoraptus - forma de estupro em que são buscadas mulheres idosas.

Apotemnofilia - excitação com a idéia de sofrer amputações. $O$ desvio complementar é a acrotomofilia (ver).

Asfixia sexual - ver Hipoxifilia.

Astenolagnia - excitação por sentir-se fraco ou em ser humilhado.

Tipo particular de masoquismo.

Autoerotismo - forma de busca solitária de prazer. Masturbação.

Autoflagelação - ver Flagelação.

Autoginefilia - excitação sexual de homens pelo uso de vestes femininas. Caso particular de Travestismo.

Autogonistofilia - forma especial de exibicionismo, em que a pessoa se excita ao ser fotografada nua.

Automisofilia - excitação sexual advinda de sentir-se sujo.

Autonepiofilia - o mesmo que Infantilismo e Anaclitismo.

Axilismo - excitação em simular sexo axilar.

B\&D (Bondage and Dominance) - prazer erótico em manter relações com o parceiro (ou parceira) amarrado. Em geral, é associado ao sadomasoquismo.

Barosmia - ver Osmolagnia.

Basoexia - o mesmo que osculocentrismo.

Belonofilia - excitação pelo uso de agulhas.

Bestialismo - ver Zoofilia.

Biastrofilia - excitação em práticas violentas de estupro.

Braquioproctosigmoidismo - ver Fistfucking.

Bouginonia - Caso especial de stretching, com prazer masturbatório pelo uso de objetos para o alargamento da vagina.

Cateterofilia - excitação pela aplicação de cateteres uretrais.

Cinofilia - excitação com cães. Um tipo particular de zoofilia.

Cisvestismo - excitação com um tipo particular de vestes, em geral uniformes de enfermeiras, garçonetes, policiais, escolares, etc.

Chuva dourada - ver Urofilia.

Cleptofilia - excitação sexual conseguida praticando roubos.

Clismafilia - uso erótico de enemas. Em geral, é associado ao sadomasoquismo.

Coprofagia - excitação pela ingestão de fezes. Ver Coprofilia.

Coprofilia - excitação pelo odor, visão ou contato com fezes, podendo chegar até ao ato de ingeri-las (coprofagia). Sinônimo de coprolagnia.

Coprolagnia - ver Coprofilia. 
Crurofilia - tipo particular de parcialismo, onde o objeto da eroticidade são as pernas.

Dacrilagnia - excitação sexual em observar o parceiro chorar.

Dendrofilia - excitação com uso de vegetais, por exemplo cenouras.

Dippoldismo - excitação pelo abuso de crianças. Tipo particular de pedofilia.

Dismorfofilia - excitação por parceiros portadores de deformidades ou deficiências físicas.

Ecdiose - excitação por desnudar-se frente à outras pessoas.

Efebofilia - atração de pessoas idosas por parceiros muito jovens.

Emetofilia - também chamado de "banho romano", é a erotização obtida com o ato de vomitar ou ver outros vomitarem.

Erotofilia - prazer erótico em falar sobre temas eróticos ou pornográficos.

Erotografomania - erotização com a escrita de textos sensuais.

Erotolalia ou Telefono-escatofilia - prazer em fazer telefonemas obscenos, geralmente de maneira anônima.

Escoptofilia - prazer na mera observação, disfarçada ou declarada, dos órgãos genitais.

Estigmatofilia - excitação com o fato de a parceria portar sinais (estigmas) como cicatrizes, piercing, tatuagens, etc.

Exibicionismo - prazer em exibir os genitais.

Falofilia - parcialismo centrado no pênis.

Fetichismo - atração por objetos, em geral peças de vestiário, como sapatos, calcinhas, etc.

Filemamania - erotização pelo beijo.

Fistfucking ou Gantização ou Braquioproctosigmoidismo ou handball ou Fisting - aparentemente uma prática sexual recente entre homossexuais, consiste na introdução da mão e punho no reto do parceiro.

Fisting - ver Fistfucking.

Flagelação - tipo especial de sadomasoquismo, em que o indivíduo tem prazer erótico em provocar dor a si próprio.

Fobofilia - excitação pelo medo ou pelo ódio.

Fratrilagnia - excitação sexual pelo irmão.

Froteurismo ou frotismo - consiste na obtenção de intenso prazer em roçar-se com pessoas do sexo oposto.

Frotismo - ver Froteurismo.

Gantização - ver Fistfucking.

Geronosexualidade - situação em que o objeto de atração sexual tem idade acima de 30 anos a mais do que o portador. É caso particular de gerontofilia.

Gerontofilia - atração sexual por pessoas de idade no mínimo 15 anos maior que a do portador. 
Ginelofilia - excitação desencadeada pela observação dos pelos pubianos.

Ginemnese - caso particular de travestismo, onde homens se excitam ao se vestirem de mulheres.

Grafelagnia - excitação a partir de fotos de sexo e nudez.

Handball - ver Fistfucking.

Hebefilia - excitação sexual por adolescentes. Caso particular de pedofilia.

Hemotigolagnia - erotização a partir de absorventes íntimos femininos.

Hidrofrodisia - excitação pelo odor da transpiração da região genital. Hipoxifilia ou asfixia sexual - excitação frente à asfixia.

Hirsutofilia - excitação com pelos corporais.

Hodofilia - excitação sexual obtida com as viagens.

Homossexualismo - atração sexual por pessoas de mesmo sexo.

Iatranudia - excitação ao se expor a um médico.

Iconolagnia ou Pigmalionismo - obtenção de prazer através do contato tátil com estátuas.

Infantilismo - ver Anaclitismo.

Koupeurintomania - Caso especial de stretching, com prazer à dilatação da vagina.

Lactofilia - o mesmo que lactomania.

Lactomania ou lactofilia - excitação por nutrizes.

Lagnolalia - excitação ao discutir temas sexuais.

Maieusiofilia - excitação desencadeada por gestantes.

Meatotomia - caso especial de stretching, com prazer à dilatação da uretra.

Menofilia - excitação por mulheres menstruadas.

Misofilia ou riparofilia - erotização com uso de roupas sujas ou de odores de decomposição. A sujeira pode ser até mesmo de restos de fezes ou urina.

Mixoscopia - ver Voyeurismo.

Nafefilia - excitação em se tocar, ou em ser tocado.

Nasofilia - parcialismo pelo nariz.

Nanofilia - atração por parceiros de baixa estatura.

Necrofilia ou Vampirismo - desejo e prática de relacionamento sexual com cadáveres. Ocorre praticamente sempre entre homens.

Nepiofilia - excitação com crianças do sexo oposto. Caso particular de pedofilia.

Ninfofilia - atração de homens adultos por moças adolescentes.

Nosofilia - excitação em ter relações com parceria portadora de doença em fase terminal.

Nudomania - o mesmo que omolagnia. 
Obesofilia - atração erótica por pessoas obesas. É uma variação praticamente exclusiva de homens.

Oculofilia-parcialismo com olhos.

Odaxelagnia - excitação com mordidas.

Ofidiofilia - excitação sexual com cobras. Caso particular de bestialismo.

Olfatofilia - ver Osmolagnia.

Omolagnia ou Nudomania - excitação com a nudez.

Ondinismo - ver Urofilia.

Osculocentrismo - excitação a partir do beijo.

Osfresiolagnia - ver Osmolagnia.

Osmolagnia ou olfatofilia ou ozolagnia ou osfresiolagnia ou barosmia - excitação com odores corporais.

Ozolagnia - ver Osmolagnia.

Parascopismo - tipo particular de voyeurismo, praticado através de janelas de dormitórios.

Parcialismo - interesse erótico por determinadas partes da anatomia, como pés, mamas, etc.

Partenofilia - desejo sexual por virgens.

Pedeictofilia - o mesmo que exibicionismo.

Pederastia ou Uranismo - é a pedofilia homossexual masculina, com penetração.

Pediofilia - excitação sexual derivadas de bonecas.

Pedofilia - atração sexual por crianças ou adolescentes muito jovens.

Pode ocorrer com ou sem desejos de coito, entre homens e mulheres heterossexuais, homossexuais ou bissexuais.

Periculofilia - erotização frente situações de tensão ou perigo.

Pigmalionismo - ver Iconolagnia.

Pigofilemania - excitação pelo beijo nas nádegas.

Pigofilia - excitação por contato com as nádegas.

Podofilia - atração erótica por pés. É um tipo particular de parcialismo.

Podolatria - situação particular de podofilia associada a componente sadomasoquista.

Politerofilia - excitação sexual somente ao ter sexo com uma série de parceiros.

Proctofilia ou analismo - fixação pelo ânus.

Rabdofilia - excitação ao ser chicoteado. É um caso particular de masoquismo.

Renifleur - pessoa que se excita em cheirar roupas íntimas.

Retifilismo - fetichismo por sapatos.

Riparofilia-mesmo que misofilia. 
Sadomasoquismo - inicialmente vistos como situações diversas (sadismo e mascquismo), admite-se hoje serem faces da mesma moeda, isto é, o indivíduo tem prazer sexual tanto em ocasionar como em sentir dor física.

Siderodromofilia - excitação com viagens de trem.

Sitofilia - excitação com comida.

Socratismo - prazer na estimulação anai.

Sodomismo - prazer na prática de coito anal, independentemente do sexo do portador.

Sororilagnia - excitação sexual e sexo com a irmă. Caso particular de incesto.

Stretching - excitação com o alargamento de partes genitais, como com o uso de espéculos ginecológicos, por exemplo. Ver meatotomia, kolpeurintomania e bouginonia.

Tantalolagnia - excitação obtida em provocar sensualmente outra pessoa.

Telefonicofilia - excitação advinda de conversas eróticas te!efônicas, tipo "Fone-Sex".

Telefono-escatofilia - ver Erotola!ia

Tesauromania - excitaçĩo em colecionar roupes íntimas de pessoas do sexo oposto.

Tigatria - sexo entre pai c tillha. Caso partictilar de incesto.

Timofilia - excitação sexual com a riqueza.

Titilagnia - excitação sexual com cócegas.

Titiolagnia - obtenção de orgasmos por nutrizes, durante o aleitamento. Tlipsosis - ex.citação por belisear outras pessoas.

Travestismo - excit:ção no uso de vestes típicas do outro sexo. Embora possa co-existir com o homossexualismo, não é obrigatório que isto ocoira.

Tricofilia - fetiche por cabelos.

Triolismo-prazer eın relacion:mento com 2 pesseas do sexo oposto. Tripsofilia - ver Tripsolanofilia.

Tripsolanofilia ou tripsofilia - excit:ç̃o desencadeada por massagens.

Uranismo - sinônimo de pederstia (vêi). Termo em desuso.

Urofilia ou Ondinis!no ou U:s'tıgn:ı o!: "Chuva Dourada"- excitação erótica associada to ato de urina: ou receber o jato urinário do parceiro, chegando, em alguns caso.s, a deglutir a urina.

Urolagnia - ver Urofilia.

Vampirismo - ver Necrofilia.

Voyerismo ou mixoscop̣ia - excitaçño advinda da observação (quase sempre clandestina) de genitais ou regiões consideradas excitantes, ou ainda de relações preticadas por outras pessoas: 
Zelofilia - excitação sexual associada ao ciúme.

Zooerastia - ver Zoofilia.

Zoofilia ou zooerastia ou bestialismo - é a atração sexual por animais.

Deve-se diferenciar a zoofilia permanente, na qual o indivíduo mantém esse desejo por toda a vida, daquela transitória, que ocorre principalmente na infância e adolescência, conseqüente a impossibilidade de encontrar parceiros humanos.

\section{BIBLIOGRAFIA RECOMENDADA}

ARIÈS, P.; BÉJIN, A. Sexualidades ocidentais. Brasiliense, São Paulo, 1985.

BIANCO, C. F. J. Manual diagnostico de las enfermedades en sexologia. Ed. do autor, Caracas, Venezuela, 1988.

BIANCO, F. Manual diagnóstico das doenças em sexologia. MEDSI, Rio de Janeiro, 1993.

CALIL, V. L. Terapia familiar e de casal. Summus, São Paulo, 1987.

CARDOSO, E. R. G. A formação profissional do psicoterapeuta. Summus, São Paulo, 1985.

CAVALCANTI, R.; CAVALCANTI, M. Inadequações sexuais. Roca, São Paulo, 1992.

CAVALCANTI, R.; VITIELLO, N. Sexologia I. 2a ed. CEICH, São Paulo, 1997.

FLORES COLOMBINO, A. Diccionario de Sexologia. Fin de Siglo, Montevideo, 1997.

FLORES COLOMBINO, A. Puesta al dia: Parafilias. Rev Argentina Sex Hum 12(1):7-35, 1999.

COSTA, M.; MONESI, A.; RODRIGUES JR, O. M. Cem dúvidas sobre sexo. Gente, São Paulo, 1993.

FUCS, G. B. Homem/mulher \& encontros e desencontros. Rosa dos Tempos, Rio de Janeiro, 1992.

HEIMAN, J.; LO PICCOLLO, L.; LO PICCOLLO, J. Descobrindo o prazer - uma proposta de crescimento sexual para a mulher. Summus Editorial, São Paulo, 1981.

HERRIN, K. O livro de sexo-exercícios. Roca, São Paulo, 1984.

KAPLAN, H. S. A nova terapia do sexo. $4^{\mathrm{a}}$ ed. Nova Fronteira, Rio de Janeiro, 1977.

KAPLAN, H. S. Desejo sexual. Nova Fronteira, Rio de Janeiro, 1983.

KOLODNY, R. C.; MASTERS, W. H.; JOHNSON, V. E. Manual de Medicina Sexual. Manole, São Paulo, 1982.

KUSNETZOFF, J. C. A mulher sexualmente feliz. Nova Fronteira, Rio de Janeiro, 1988.

KUSNETZOFF, J. C. O homem sexualmente feliz. Nova Fronteira, Rio de Janeiro, 1990.

LEIBLUM, S. R.; PERVIN, L. A. (orgs.) Princípios e prática da terapia sexual. Zahar, Rio de Janeiro, 1982.

LOPES, G. P. \& cols. Patologia e Terapia Sexual. Medsi, Rio de Janeiro, 1994. 
MANNOCCI, J. F.; RODRIGUES JR, O. M.; CONCEIÇÃO, I. S. C.; VITIELLO, N. Disfunções Sexuais: abordagem clínica e terapêutica. Fundo Editorial BYK, São Paulo, 1995.

MASTERS, W. H.; JOHNSON, V. E. A inadequação sexual humana. Roca, São Paulo, 1985.

MEYER, J. K. (org.) Tratamento clínico dos distúrbios sexuais. Manole, São Paulo, 1977.

MUNJACK, D. Sexologia; diagnóstico e tratamento. Atheneu, Rio de Janeiro, 1984.

PUECH-LEÃO, P.; GLINA, S. Os órgãos de Adão. Marco Zero, São Paulo, 1990.

RODRIGUES JR, O. M. Psicologia e sexualidade. Medsi, Rio de Janeiro, 1995.

STORR, A. Desvios sexuais. Zahar, Rio de Janeiro, 1976.

TRIMMER, E. Medicina sexual básica. Manole, São Paulo, 1980.

VITIELLO, N. Reprodução e sexualidade. Um manual para educadores. $\mathrm{CEICH}$, São Paulo, 1994.

VITIELLO, N. Sexologia II. 2a ed. CEICH, São Paulo, 1997.

VITIELLO, N. Sexualidade - Quem educa o educador. São Paulo, Editora Iglu, 1997.

VITIELLO, N.; RODRIGUES JR, O. M. As bases anatômicas e funcionais do exercício da sexualidade. Iglu, São Paulo, 1997. 